\title{
UK Open Access Life Cycle
}

\section{for Researchers}

Key

\section{University/Library}

Publishers

Jisc/Above campus

OAWAL

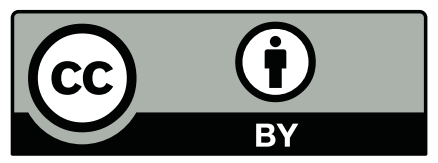

Stone, Graham, Stainthorp, Paul, Awre, Chris and Emery, Jill (2015).

UK Open Access Life Cycle for Researchers http://dx.doi.org/10.5920/UKOARES.2016

Sherpa

(journal

policies)

Discovery IRUS - UK
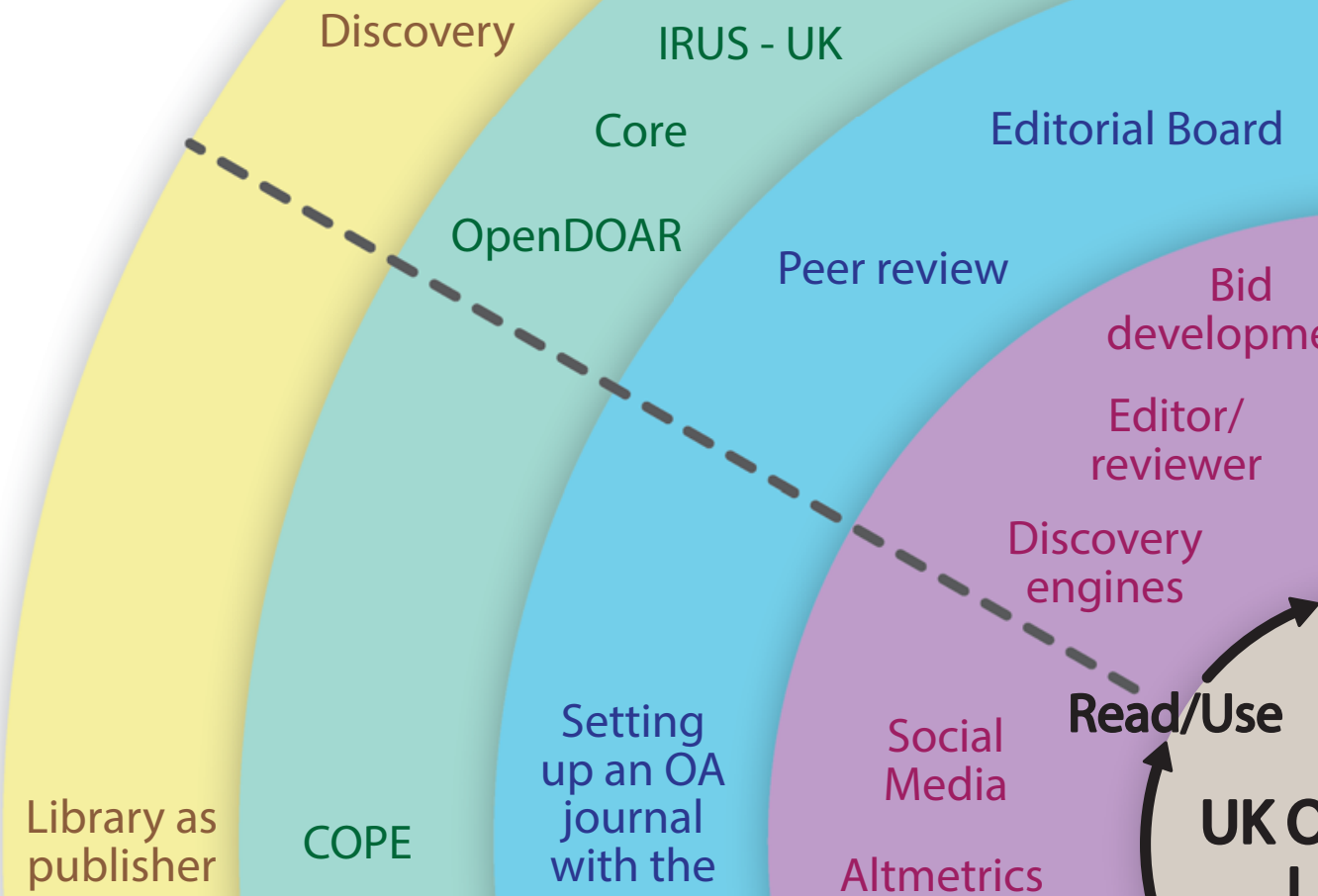

Editor/

reviewer

Discovery

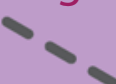

Read/Use

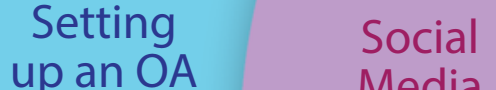

up an OA

with the

Press/

library

Altmetrics

Read/Use

Submit

Juliet

under policies)

Sherpa

Fact (RCUK

compliance)

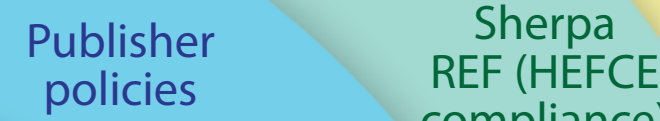

policies compliance)

policy

support

Awards Journal

Awards Journal
Management choice

compliance)

ORCID Fundref

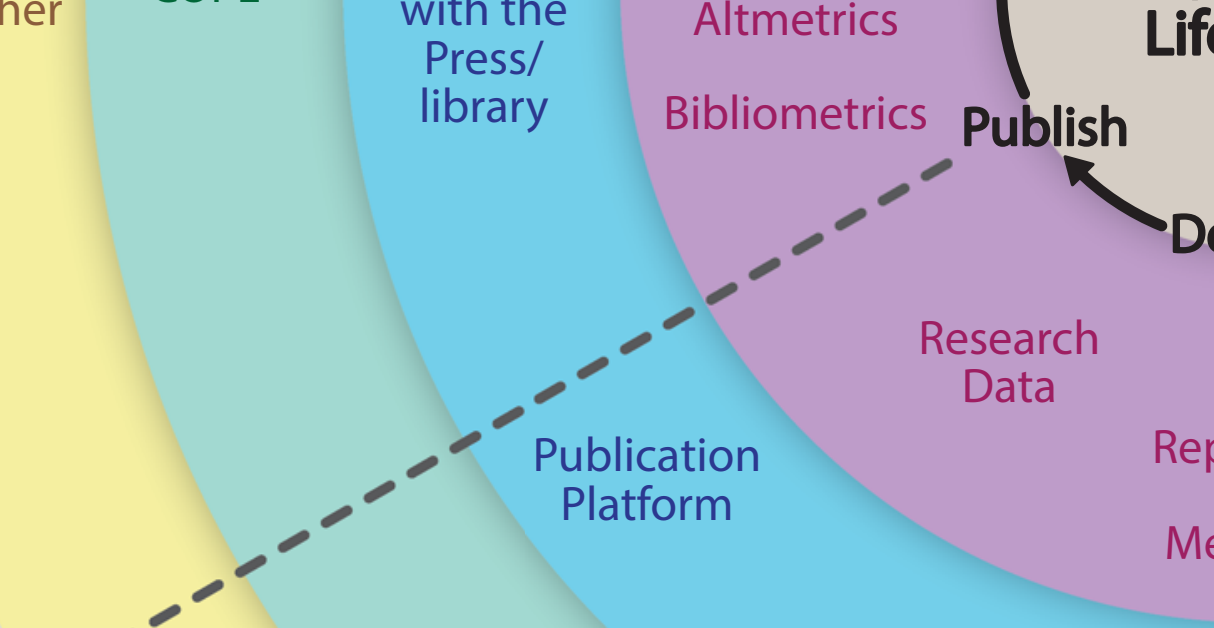

h
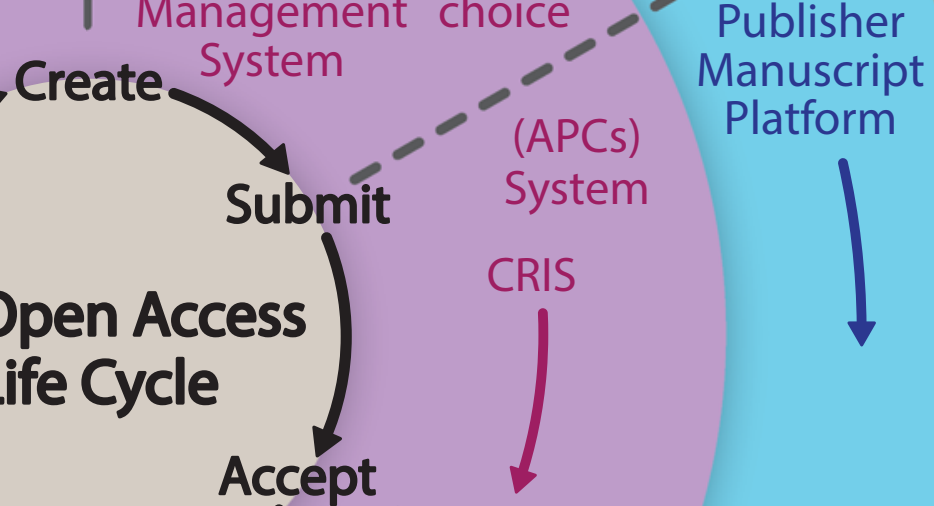

ISNI
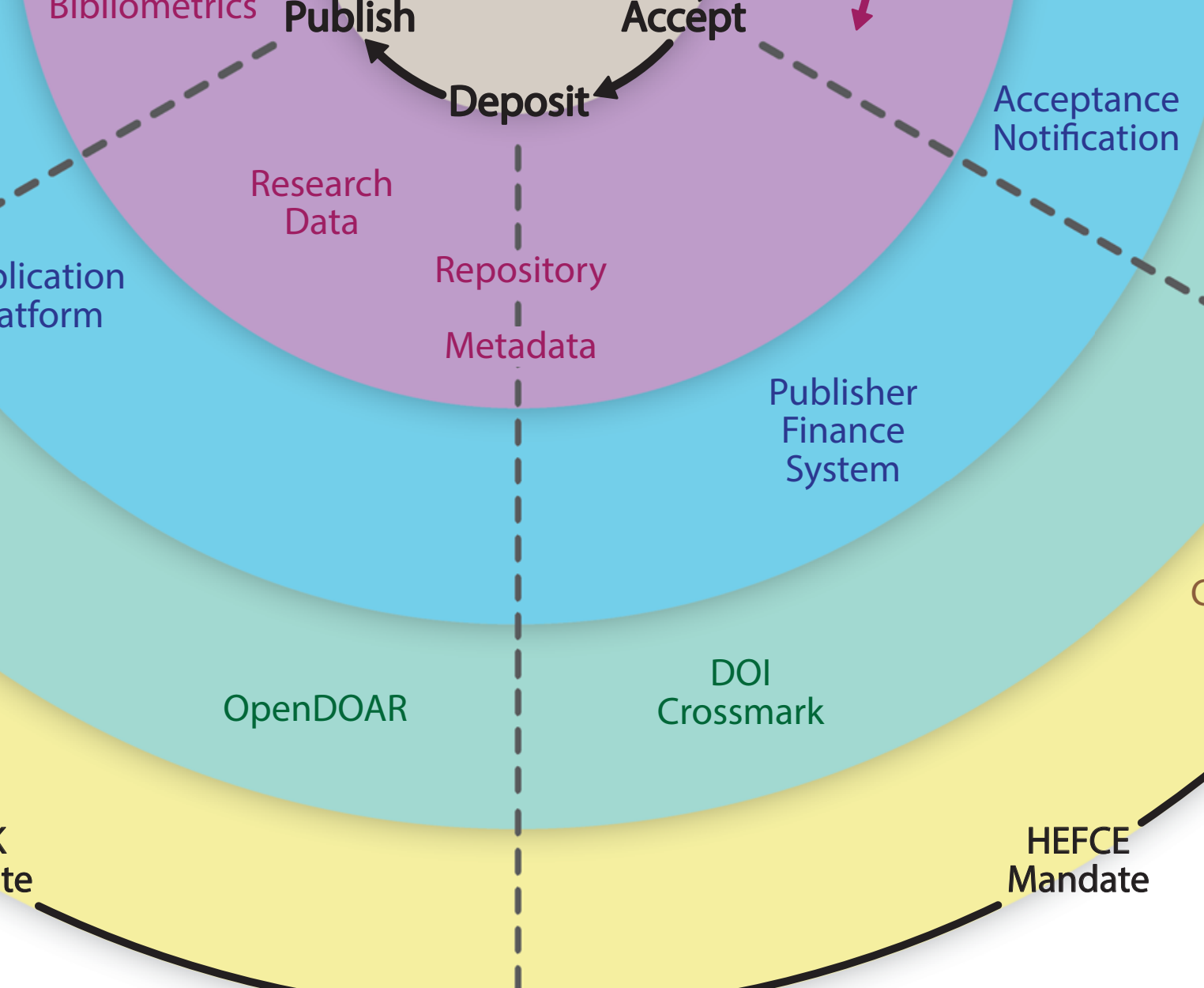